\title{
Discrimination and Authentication of Eclipta prostrata and E. alba Based on the Complete Chloroplast Genomes
}

\author{
Inseo Kim', Jee Young Park', Yun Sun Lee', Hyun Oh Lee', Hyun-Seung Park', Murukarthick Jayakodi', \\ Nomar Espinosa Waminal ${ }^{1}$, Jung Hwa Kang ${ }^{3}$, Taek Joo Lee ${ }^{3}$, Sang Hyun Sung ${ }^{4}$, Kyu Yeob Kim ${ }^{5}$, Tae-Jin Yang ${ }^{1 *}$ \\ ${ }^{1}$ Department of Plant Science, Plant Genomics and Breeding Institute, and Research Institute of Agriculture and Life Sciences, \\ College of Agriculture and Life Sciences, Seoul National University, Seoul 08826, Korea \\ ${ }^{2}$ Phyzen Genomics Institute, Seongnam 13558, Korea \\ ${ }^{3}$ Hantaek Botanical Garden, Yongin 17183, Korea \\ ${ }^{4}$ College of Pharmacy and Research, Institute of Pharmaceutical Science, Seoul National University, Seoul 08826, Korea \\ ${ }^{5}$ Herbal Research Division, Ministry of Food and Drug Safety, Cheongju 28159, Korea
}

\begin{abstract}
Eclipta prostrata and E. alba are annual herbal medicinal plants and have been used as Chinese medicinal tonics. Both species are widely distributed in tropical and subtropical regions as well as in Korea. Both species have similar morphological features but $E$. alba has smoother leaf blade margins compared with E. prostrata. Although both species are utilized as oriental medicines, $E$. prostrata is more widely used than E. alba. Morphological semblances have confounded identification of either species. Here, we report the complete chloroplast genomes of both species to provide an authentication system between the two species and understand their diversity. Both chloroplast genomes were 151,733-151,757 bp long and composed of a large single copy (83,285-83,300 bp), a small single copy (18,283-18,346 bp), and a pair of inverted repeats (25,075-25,063 bp). Gene annotation revealed 80 protein coding genes, 30 tRNA genes and four rRNA genes. A phylogenetic analysis revealed that the genus Eclipta is grouped with Heliantheae tribe species in the Asteraceae family. A comparative analysis verified 29 InDels and 58 SNPs between chloroplast genomes of E. prostrata and $E$. alba. The low chloroplast genome sequence diversity indicates that both species are really close to each other and are not completely diverged yet. We developed six DNA markers that distinguish E. prostrata and E. alba based on the polymorphisms of chloroplast genomes between E. prostrata and E. alba. The chloroplast genome sequences and the molecular markers generated in this study will be useful for further research of Eclipta species and accurate classification of medicinal herbs.
\end{abstract}

Keywords Eclipta prostrata, E. alba, Medicinal herbs, Chloroplast sequence, Molecular marker

\section{INTRODUCTION}

Eclipta prostrata is an annual herbaceous plant belonging to the family Asteraceae which includes 1,620 genera and 23,600 species (Mithun et al. 2011). It is distributed in tropical and subtropical regions including South America, Asia, Africa, and south of the central region in Korea (Chokotia et al. 2013). It has tap roots and many brown branches. Also, it has two types of flowers, ray florets and disc florets, with involucre of bracts that arrange in two lines (Neeraja and Margaret 2012). E. alba is also included in the family Asteraceae and has very similar shapes with $E$. prostrata except for smoother margins of leaf blades. E. prostrata has been used as a medicinal plant owing to compounds like Eclalbasaponin I and wedelolactone found in the plant which have antitumor and cirrhosis and hepatitis curing effects (Dalal et al. 2010; Liu et al. 2012). In addition, it has been used as resources for

Received November 20, 2017; Revised November 22, 2017; Accepted November 22, 2017; Published December 1, 2017

*Corresponding author Tae-Jin Yang, tjyang@snu.ac.kr, Tel: +82-2-880-4557, Fax: +82-2-873-2056 
Chinese tonics to cure loose teeth, tinnitus, hemoptysis, hematuria and uterine bleeding (Chinese Pharmacopoeia Commission 2010). Similarly, E. alba has been used as a medicinal plant owing to its flavonoids that could induce anagen, which helps blackening hairs (Datta et al. 2009). Due to similar morphological traits and widely shared habitats (Baskaran and Jayabalan 2005; Dhaka and Kothari 2005), E. alba is often mixed with E. prostrata (Muruganantham et al. 2009), which cause confusion in the academic world as well as the markets (Neeraja and Margaret 2012). Therefore, it is necessary to develop a high-throughput system to discriminate them for efficient genetic research and sustain its market value.

Chloroplast genomes are maternally-inherited (Cheng et al. 2005; Dong et al. 2012), rarely apt to occur recombination and mutation events. Chloroplast genome possesses significant interspecific variations and has widely been used for classification of plant species. Interspecific taxonomic studies have been conducted based on chloroplast genomes in Scalesia affinis, Abies, and Citrus species (Parducci et al. 2001; Nielsen et al. 2004; Cheng et al. 2005). Chloroplast DNA markers are still a useful tool for species classification. Recently, some researches had been performed to discriminate species with molecular markers based on chloroplast genomes of Cynanchum wilfordii, Cynanchum auriculatum and Polygonum multiflorum (Kim et al. 2013; Jang et al. 2015; Kim et al. 2015c; Park et al. 2015).

Previously, we reported the chloroplast genome for $E$. prostrata (Park et al. 2016). In this study, we assembled the complete chloroplast genome of E. alba. In addition, we have conducted a comparative phylogenetic analysis of $E$. $a l b a$ and E. prostrata along with 10 species that belong to the Asteraceae family. In addition, we show genome-level diversity between the closely related Eclipta species and have developed polymorphic markers that could efficiently distinguish E. alba and E. prostrata and thus can practically be applied for authentication of those species for adequate use of these medicinal herbs.

\section{MATERIALS AND METHODS}

\section{Plant materials and genome sequencing}

E. prostrata and E. alba plants used in this study were collected from HanTaek Botanical Garden (Yongin, Korea, www.hantaek.co.kr) and Jeju Island, respectively. Specimens of dried Eclipta plant tissues were provided by Ministry of Food and Drug Safety. Genomic DNAs of $E$. prostrata and E. alba were extracted from leaf tissues by a modified cetyltrimethlammonium bromide (CTAB) method (Allen et al. 2006), and the DNA of the specimens were extracted from each of the whole, stem, and leaf tissues by Genomic Plus DNA Prep kit (Inclone, Korea). The whole tissues of specimens were composed of stems, leaves, and flowers. The quality and quantity of extracted DNA were checked using Nanodrop ND-1000 (Thermo scientific, Wilmington, USA). Paired-end sequencing (PE) was conducted using Illumina MiSeq platform by LabGenomics (www.labgenomics.co.kr, Seongnam, Korea).

\section{Chloroplast genome assembly}

Raw paired-end (PE) reads were trimmed and de novo assembled using the method as described by Kim et al. (2015a, 2015b). From initial assembly, contigs representing chloroplast genome were retrieved, ordered, and combined into a single sequence by comparing chloroplast genome sequence of Centaurea diffusa (KJ690264). The assembled sequence was manually corrected and gap-filled by a series of PE read mapping. The assembled chloroplast genome was annotated using DOGMA (http://dogma.ccbb.utexas. edu) and manually corrected with BLAST search.

\section{Phylogenetic analysis}

Phylogenetic analysis was conducted using multiple sequence alignments of 29 protein coding gene sequences ( $p s a I / J, p s b B / C / D / H / I / K / T$, petA/B/D/G/N/L, atp $A / F / H / I$, $n d h B, r p o B / C 2, r p s 2 / 7 / 18, r p l 2, a c c D, y c f 2 / 4)$ in 12 chloroplast genomes (Chrysanthemum $\times$ morifolium, JQ362483; Chrysanthemum indicum, JN867589; Artemisia montana, KF887960; Artemisia frigida, JX293720; Aster spathulifolius, KF279514; Leontopodium leiolepis, KM267636; Helianthus annuus, DQ383815; Eclipta prostrata, KU361242; Eclipta alba, MF993496; Guizotia 
abyssinica, EU549769; Jacobaea vulgaris, HQ234669;

Lactuca sativa, AP007232) belonging to the Asteraceae family. Phylogenetic tree was constructed using MEGA6.0 (Tamura et al. 2013) with the parameters of neighborjoining method and 1000 bootstrap.

\section{Comparison of inter-species level and development of molecular marker}

Sequence variations were identified by mVISTA program (http://genome.lbl.gov/vista/mvista/submit.shtml) and the polymorphic regions were found using MAFFT

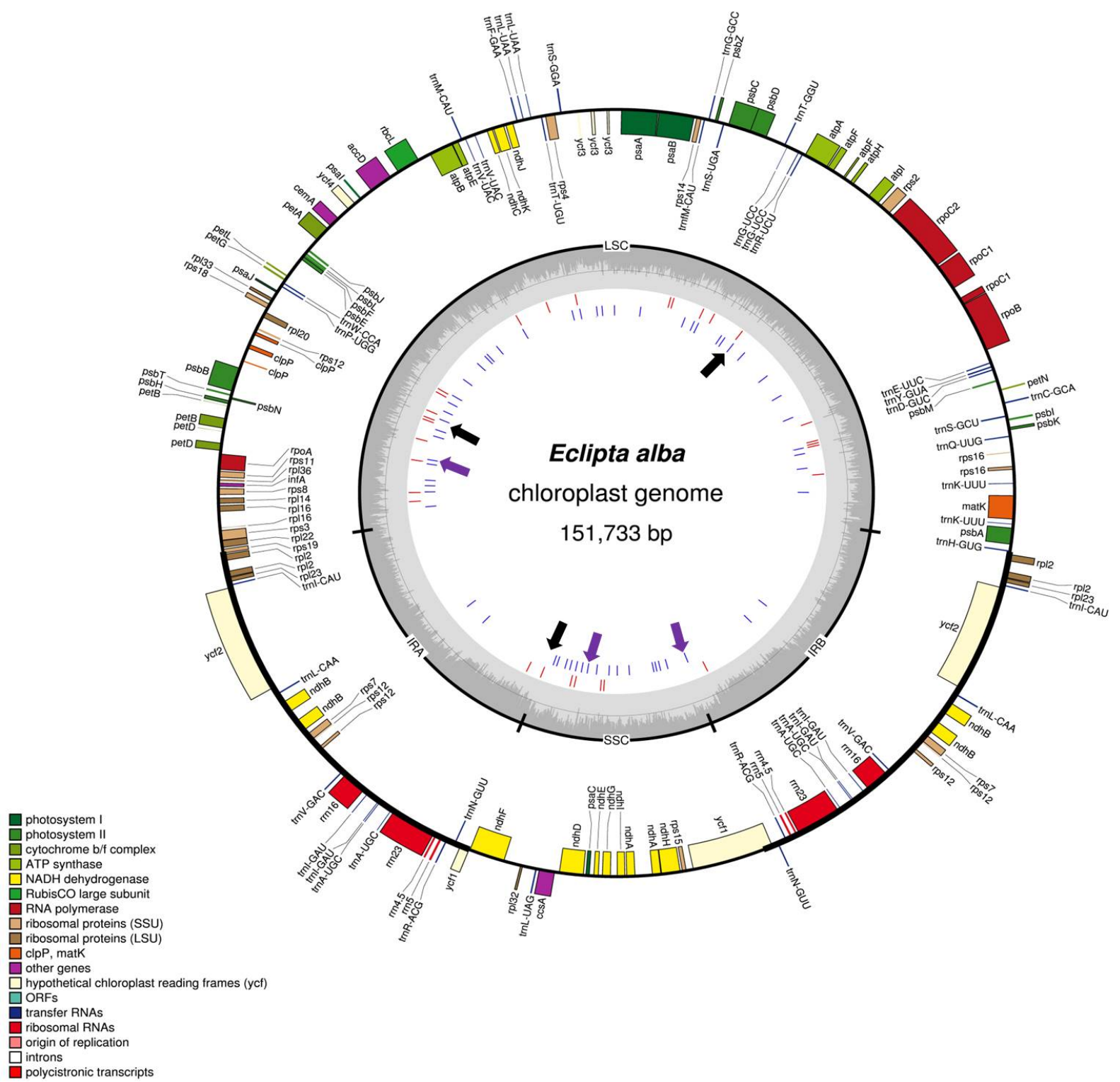

Fig. 1. Chloroplast genome map of $E$. alba and inter-species polymorphic DNA markers. Chloroplast genome map of $E$. alba was generated using OGDRAW (http://ogdraw.mpimp-golm.mpg.de/). Genes transcribed clockwise and counterclockwise are indicated on the outside and inside of the large circle, respectively. The four parts of the chloroplast genome and GC content are indicated on the inner circle. Red and blue bars in the inner circle indicate InDels and SNPs, respectively, identified between E. prostrata and E. alba chloroplast genome sequences. Black arrows represent the target regions for InDel markers and the purple arrow indicates SNP marker to differentiate E. prostrata and E. alba. 
program (http://mafft.cbrc.jp/alignment/software). The two types of molecular markers, InDel and SNP, were developed based on the polymorphic sites in chloroplast genomes of E. prostrata and E. alba. The primers were designed using NCBI Primer-blast (https://www.ncbi.nlm. nih.gov/tools/primer-blast/). PCR reaction for InDel markers was conducted in a total volume of $25 \mu \mathrm{L}$. The reaction mixtures consisted of $20 \mathrm{ng}$ of template DNA, 1x PCR buffer (Vivagen, South Korea), $2.5 \mathrm{mM}$ dNTP (Vivagen, South Korea), 10 pmol of each primer, and 2 units $/ \mu \mathrm{L}$ of Taq DNA polymerase. PCR conditions were as follows: 5 minutes at $95^{\circ} \mathrm{C}$, following 35 cycles of 30 seconds at $95^{\circ} \mathrm{C}, 30$ seconds at $58^{\circ} \mathrm{C}, 30$ seconds at $72^{\circ} \mathrm{C}$, and a final extension at $72^{\circ} \mathrm{C}$ for 5 minutes. PCR amplicons were checked on $3 \%$ agarose gel in condition of being stained by Inclone ${ }^{\mathrm{TM}}$ Safe Gel stain. Then they were visualized under UV-trans-illuminator with a gel documentation system.

PCR reaction for SNP markers was performed in a total volume of $20 \mathrm{uL}$. The mixtures were composed of $20 \mathrm{ng}$ of template DNA, 1x PCR buffer (Vivagen, South Korea), 2.5 mM dNTP (Vivagen, South Korea), 10 pmol of each primer, 2 units/uL of Taq DNA polymerase, and fluorescent dye SYTO 9 (Roche Diagnostics, IN). The PCR conditions were as follows: 5 minutes at $95^{\circ} \mathrm{C}$, following 35 cycles of 20 seconds at $95^{\circ} \mathrm{C}, 20$ seconds at $58^{\circ} \mathrm{C}, 30$ seconds at $72^{\circ} \mathrm{C}$. Then, HRM analysis was conducted using LightCycler 480 (Roche Applied Science) with the conditions that were as follows: 1 minute at $95^{\circ} \mathrm{C}$, 1 minute at $40^{\circ} \mathrm{C}, 5$ seconds at $70^{\circ} \mathrm{C}$ and the temperature increased to $90^{\circ} \mathrm{C}$, then cooled down to $40^{\circ} \mathrm{C}$ as fluorescence acquisition.

\section{RESULTS}

\section{Complete chloroplast genome and inter-species polymorphism between $E$. alba and $E$. prostrata}

The completed chloroplast genome of E. alba is a circular molecule of $151,733 \mathrm{bp}$ long and has typical quadripartite structure composed of a large single copy (LSC) region of $83,300 \mathrm{bp}$, small single copy (SSC) region of 18,283 bp and a pair of inverted repeats (IRa and IRb) of 25,075 bp (Fig. 1, Table 1). A total of 114 genes including 80 protein coding genes, 30 tRNA genes, and four rRNA genes (Table 2) were annotated and the GC content of the chloroplast genome was $37.49 \%$.

In comparison, the overall chloroplast genome size of $E$. alba showed 24-bp shorter than that of E. prostrata. E. alba is 15-bp and 24-bp longer than E. prostrata in the LSC and IR regions, respectively. In the SSC region, E. alba is 63-bp shorter than E. prostrata. A total of 58 SNPs and 29 InDels were identified between E. alba and E. prostrata. Among the polymorphic sites, 39 SNPs and 29 InDels are identified at intergenic regions and remaining 19 SNPs were identified in the genic regions.

\section{Phylogenetic analysis}

Phylogenetic analysis was conducted using protein coding gene sequences in the chloroplast genomes of $E$. prostrata, E. alba and 10 species from the Asteraceae family. E. prostrata and E. alba showed very narrow genetic diversity as being grouped together. As expected, this result showed that E. prostrata and E. alba were grouped with Heliantheae tribe species (Fig. 2) and exhibited close relationship to the species in Senecioneae and Cichorieae in the Asteraceae family. The clade, including Eclipta species, showed a sister relationship with species belonging to the Astereae, Gnaphalieae and Anthemideae.

Table 1. Summary of NGS data and chloroplast genomes of E. alba and E. prostrata.

\begin{tabular}{|c|c|c|c|c|c|c|c|}
\hline $\begin{array}{l}\text { Collected } \\
\text { species }\end{array}$ & $\begin{array}{c}\text { Raw data bases } \\
\text { (bp) }\end{array}$ & $\begin{array}{l}\text { Cp genome } \\
\text { coverage }(\mathrm{x})\end{array}$ & $\begin{array}{l}\text { Cp length } \\
\text { (bp) }\end{array}$ & $\begin{array}{l}\text { GenBank } \\
\text { accessions }\end{array}$ & $\begin{array}{l}\text { LSC length } \\
\text { (bp) }\end{array}$ & $\begin{array}{l}\text { IR length } \\
\text { (bp) }\end{array}$ & $\begin{array}{c}\text { SSC length } \\
\text { (bp) }\end{array}$ \\
\hline E. alba & $1,027,482,009$ & 89.31 & 151,733 & MF993496 & 83,300 & 25,075 & 18,283 \\
\hline E. prostrata ${ }^{\mathrm{z})}$ & $1,473,824,997$ & 317.69 & 151,757 & KU361242 & 83,285 & 25,063 & 18,346 \\
\hline
\end{tabular}

\footnotetext{
${ }^{\mathrm{z})}$ Reported by Park et al. (2016).
} 
Table 2. Information of annotated genes in chloroplast genome of E. alba.

\begin{tabular}{ll}
\hline \multicolumn{1}{c}{ Gene types } & \multicolumn{1}{c}{ Gene list } \\
\hline \hline Photosystem I & $p s a A, B, C, I, J$ \\
Photosystem II & $p s b A, B, D, E, F, H, I, J, K, L, M, N, T, Z$ \\
Cytochrome b6/f complex & $p e t A, B, D, G, N, L$ \\
ATP synthase & $a t p A, B, E, F, H, I$ \\
NADH oxidoreductase & $n d h A, B, C, D, E, F, G, H, I, J, K$ \\
RubisCO large subunit & $r b c L$ \\
RNA polymerase & $r p o A, B, C 1, C 2$ \\
Ribosomal proteins (SSU) & $r p s 2,4,7,8,11,12,14,15,16,18,19$ \\
Ribosomal proteins (LSU) & $r p l 2,14,16,20,22,23,32,33,36$ \\
clpP, matK & $c l p P, m a t K$ \\
Other genes & $c c s A, c e m A, a c c D, i n f A$ \\
Hypothetical chloroplast reading frames & $y c f 1,2,3,4,15$ \\
Transfer RNAs & $t r n A-U G C, C-G C A, D-G U C, E-U U C, F-G A A, f M-C A U, G-G C C$, \\
& $G-U C C, H-G U G, I-C A U, I-G A U, K-U U U, L-C A A, L-U A A, L-U A G$, \\
& $M-C A U, N-G U U, P-U G G, Q-U U G, R-A C G, R-U C U, S-G C U, S-G G A$, \\
& $S-U G A, T-G G U, T-U G U, V-G A C, V-U A C, W-C C A, Y-G U A$ \\
Ribosomal RNAs & $r r n 4.5,5,16,23$ \\
\hline
\end{tabular}

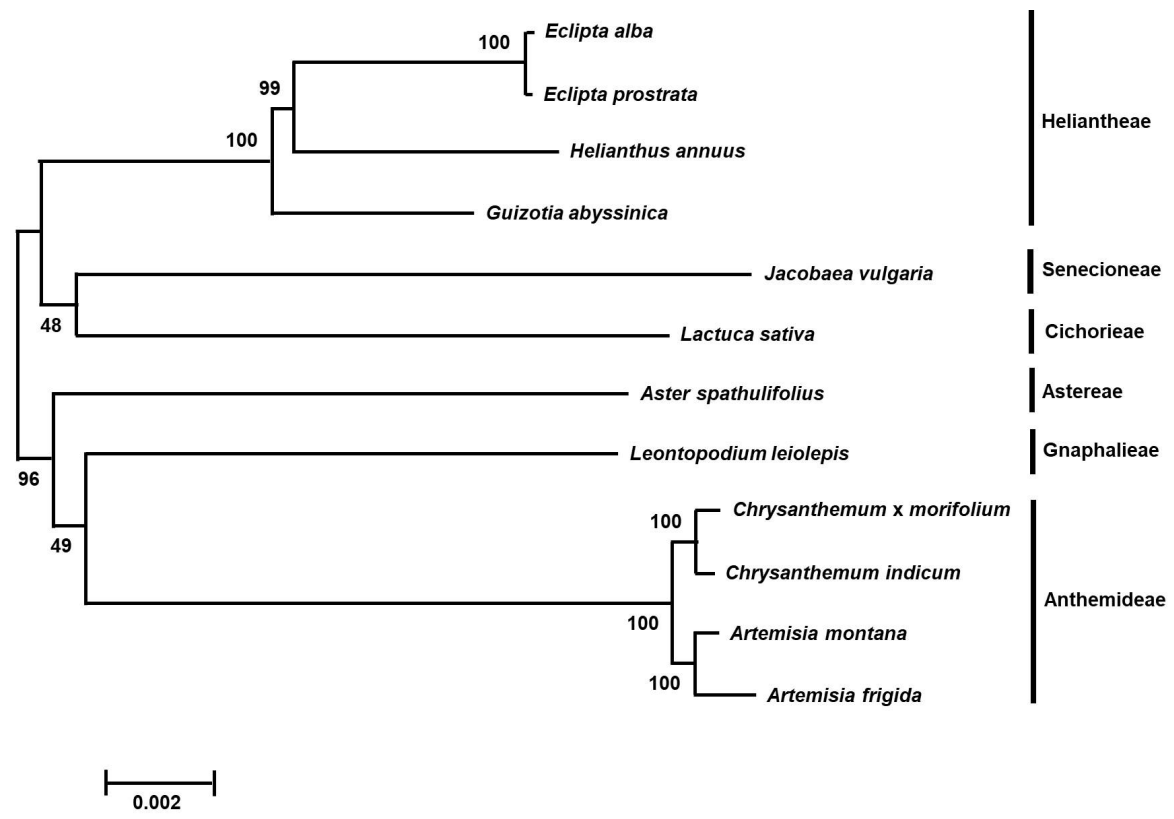

Fig. 2. Phylogenetic analysis of E. prostrata and E. alba. The tree was generated with protein coding gene sequences in chloroplast genomes of E. prostrata, E. alba and 10 species belonging to the Asteraceae family by multiple alignment using MAFFT (http://mafft.cbrc.jp/alignment/server/index.html) and a neighbor-joining (NJ) analysis using MEGA 6.0 (Tamura et al. 2013). Numbers in the nodes are bootstrap support values ( $>50 \%$ ) from 1000 replicates.

\section{Molecular markers to distinguish $E$. alba and E. prostrata}

Six inter-species polymorphic markers were developed from polymorphic regions (Table 3). The PCR amplicons showed 266/284 bp, 283/267 bp, and 230/284 bp difference (E. prostrata/E. alba) for three InDel markers, ep_01, ep_02 and ep_03, respectively, as expected (Fig. 3). 
Table 3. Details of molecular markers developed in this study.

\begin{tabular}{|c|c|c|c|c|c|c|}
\hline Type & Marker name & $\begin{array}{l}\text { Target } \\
\text { region }\end{array}$ & & Primer sequence & Variation & $\begin{array}{l}\text { Product size } \\
\text { (bp) }\end{array}$ \\
\hline \multirow[t]{6}{*}{ InDel } & \multirow[t]{2}{*}{ ep_01 } & \multirow[t]{2}{*}{ atpI-atpH } & $\mathrm{F}$ & TGTCAAGGGTTAGACGCATCC & \multirow[t]{2}{*}{$18 \mathrm{bp}$} & \multirow[t]{2}{*}{$266 / 284$} \\
\hline & & & $\mathrm{R}$ & TGTCCCGAATCGCTCTTTGA & & \\
\hline & \multirow[t]{2}{*}{ ep_02 } & \multirow[t]{2}{*}{$c l p P$} & $\mathrm{~F}$ & AGAACCAGCAGGTTGATGGA & \multirow[t]{2}{*}{$16 \mathrm{bp}$} & \multirow[t]{2}{*}{$283 / 267$} \\
\hline & & & $\mathrm{R}$ & TTCCTCCGAAAGGAAGGGTG & & \\
\hline & \multirow[t]{2}{*}{ ep_03 } & \multirow[t]{2}{*}{$y c f 1-n d h F$} & $\mathrm{~F}$ & TCGATGCAACAGCAAGATGC & \multirow[t]{2}{*}{$54 \mathrm{bp}$} & \multirow[t]{2}{*}{$230 / 284$} \\
\hline & & & $\mathrm{R}$ & AAATCATTAGGGGGTGGACG & & \\
\hline \multirow[t]{6}{*}{ SNP } & \multirow[t]{2}{*}{ ep_hrm_01 } & \multirow[t]{2}{*}{$\operatorname{ccs} A$} & $\mathrm{~F}$ & GTGGCGACTCTAGGCTTTCT & \multirow[t]{2}{*}{$\mathrm{G} / \mathrm{A}$} & \multirow[t]{2}{*}{179} \\
\hline & & & $\mathrm{R}$ & TCGCCGGTTGAGACAAGATT & & \\
\hline & \multirow[t]{2}{*}{ ep_hrm_02 } & \multirow[t]{2}{*}{$y c f 1$} & $\mathrm{~F}$ & TCTCTACGACGTTTAGACGATAAAA & \multirow[t]{2}{*}{$\mathrm{T} / \mathrm{G}$} & \multirow[t]{2}{*}{155} \\
\hline & & & $\mathrm{R}$ & AAGCACCAAAGTAATCAAAGATACC & & \\
\hline & \multirow[t]{2}{*}{ ep_hrm_03 } & \multirow[t]{2}{*}{$\operatorname{pet} B$} & $\mathrm{~F}$ & TATTGCCGCTTCTTACTGCG & \multirow[t]{2}{*}{$\mathrm{T} / \mathrm{C}$} & \multirow[t]{2}{*}{146} \\
\hline & & & $\mathrm{R}$ & ACTATAGTTCCTACCCCAAGTGAT & & \\
\hline
\end{tabular}

(a)

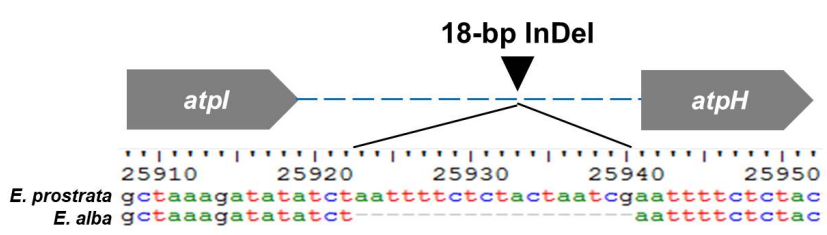

(b)

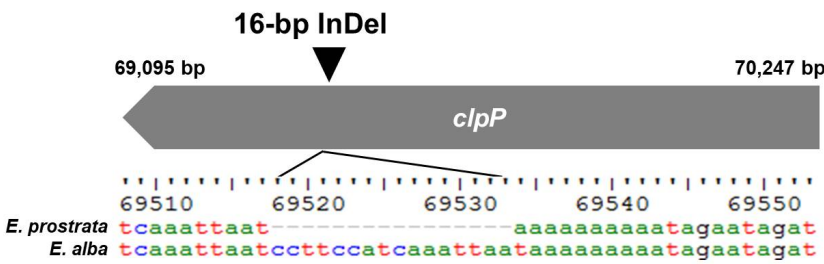

(c)

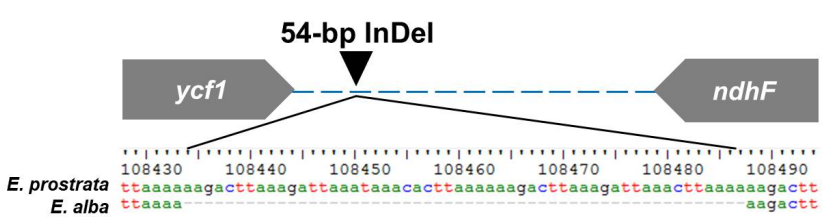

(d)

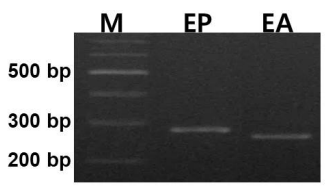

(e)

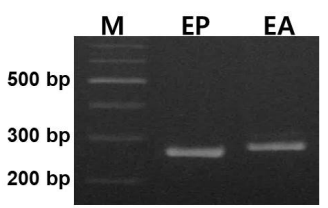

(f)

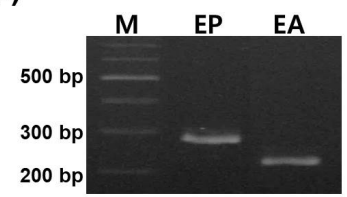

Fig. 3. Three InDel-based markers to discriminate between E. prostrata and E. alba. (a) A 18-bp InDel in atpI-atpH and (d) its PCR products for E. prostrata and E. alba. (b) A 16-bp InDel in $c l p P$ and (e) its PCR products for $E$. prostrata and E. alba. (c) A 54-bp InDel in $y c f 1-n d h F$ and (f) its PCR products for E. prostrata (EP) and E. alba (EA). M: 100-bp DNA ladder.

Meanwhile, three SNP markers, ep_hrm_01, ep_hrm_02, and ep_hrm_03 discriminated E. prostrata from E. alba based on HRM analysis (Fig. 4).

\section{Application of InDel markers to randomly collected Eclipta herbal medicinal products}

Three InDel-based markers were applied to five random specimens provided by Ministry of Food and Drug Safety to authenticate their source whether from E. prostrata or $E$. alba. The specimens include collections of dried plant tissues which utilized as oriental medicines. PCR analysis conducted with the InDel-based markers applying to the each form (bulk form, stem form, leaf form, another leaf form) of all samples. Both sizes of PCR amplicons, 
(a)

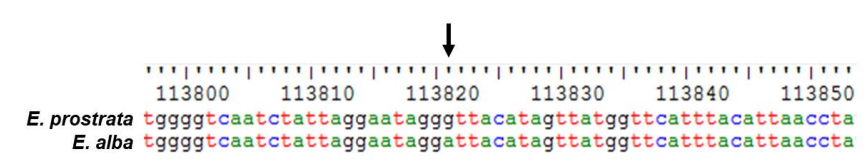

(b)

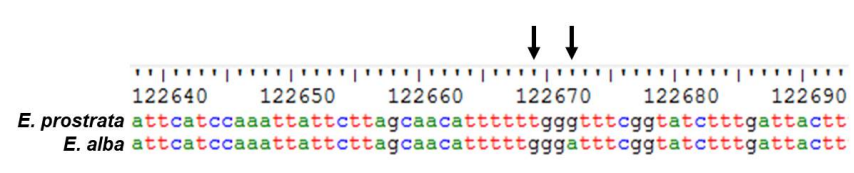

(c)

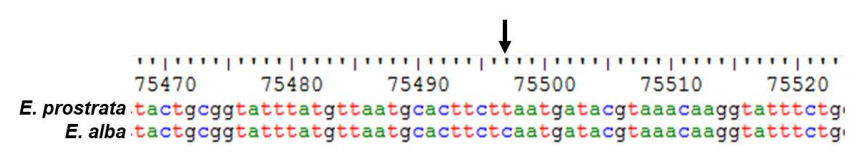

(d)

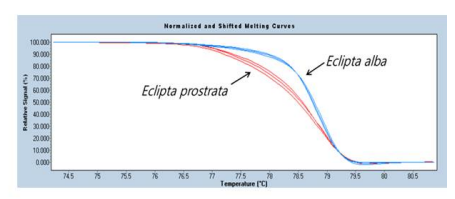

(e)

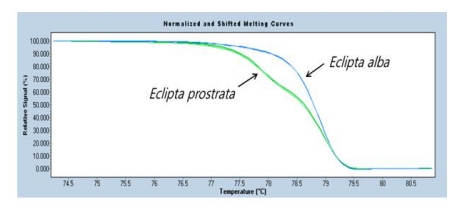

(f)

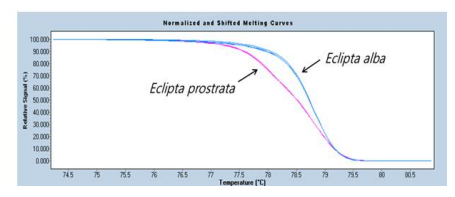

Fig. 4. Three SNP-based markers to distinguish E. prostrata and E. alba. Alignment of nucleotide sequences to show the SNPs (arrow) in (a) $\operatorname{css} A$, (b) $y c f 1$ and (c) petB gene of chloroplast genomes of E. prostrata and E. alba, and (d-f) HRM analysis to detect each of the three SNPs. M: 100-bp DNA ladder.

(a)

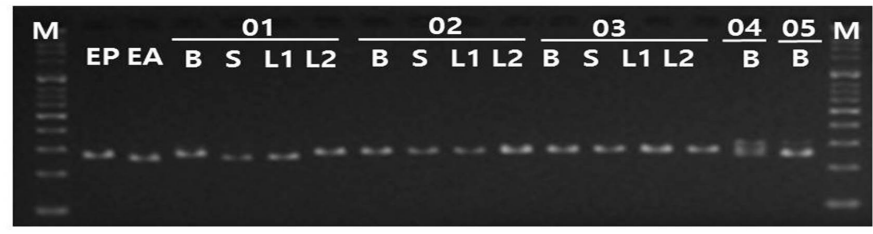

(b)

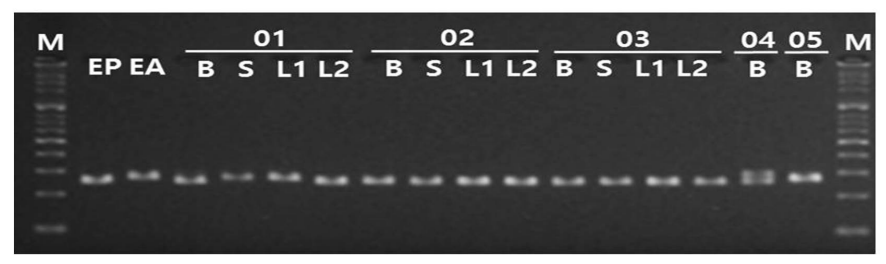

(c)

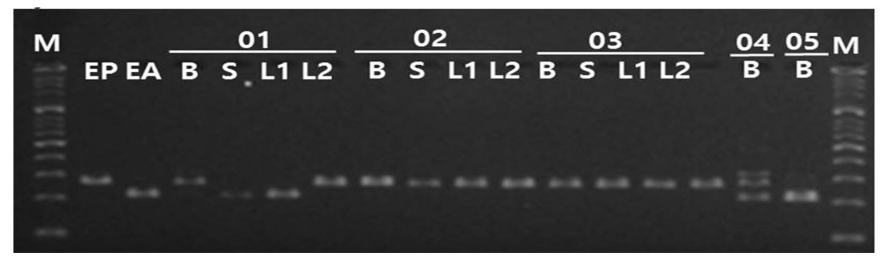

Fig. 5. Application of InDel markers to five bulk Eclipta samples. The three InDel markers, (a) ep_01, (b) ep_02, (c) ep_03 were applied to E. prostrata, E. alba, and five random specimens in each form of bulk, stem, and leaves. M: 100bp ladder, EP: E. prostrata, EA: E. alba, 01-05: The names of the random specimens, B: bulk form, S: stem form, L1: leaf form, L2: another leaf form. 
266/284 bp, 283/267 bp, and 230/284 bp differences, were shown for three InDel markers, respectively in the sample 01. (Fig. 5). The results indicated that these medicinal herbs are being sold with the state of mixing in the markets.

\section{DISCUSSION}

\section{Discrimination of $E$. alba and $E$. prostrata with six molecular markers}

Despite different medicinal effects of E. alba from those of E. prostrata, it has been confused often with E. prostrata in the market and academic world because of their similar morphology and widely shared distribution (Baskaran and Jayabalan 2005; Dhaka and Kothari 2005). Thus, it is essential to develop a unique system to investigate $E$. prostrata and E. alba to protect against false trading (Neeraja and Margaret 2012).

Here, we generated the complete chloroplast genome of E. alba and identified 87 inter-species polymorphic sites, 58 SNPs and 29 InDels, between E. prostrata and E. alba. These polymorphic regions could be applied to phylogenetic analysis and development of molecular markers for discrimination of E. prostrata and E. alba. Phylogenetic analysis revealed that E. prostrata and E. alba are really close and grouped with Heliantheae species (Fig. 2). Overall phylogenetic result is consistent with a previous study (Park et al. 2016).

In this study, we report six markers that can be applied for classification of E. prostrata and E. alba, and for authentication of five random specimens of dried Eclipta plant tissues. Three InDel-based markers successfully distinguished E. prostrata from E. alba and three SNP markers effectively divided the melting patterns of $E$. prostrata from E. alba with HRM analysis. Overall, the results suggest that these molecular markers could contribute to ascertain the exact medicinal resources between those species.

\section{Authentication of Eclipta products with three InDel-based markers}

For further validation of InDel-based markers and authentication of random Eclipta medicinal herbs, we conducted PCR analysis with the InDel-based markers developed in this study (Figs. 4 and 5). All InDel-based markers efficiently discriminated E. prostrata from E. alba as previously proved in this research. However, sample no. 01 showed both genotypes for the markers, indicating that the products contain tissues from both species (Fig. 5).

Through this analysis, we presented an instance of admixture between E. prostrata and E. alba in the market. Both species show very similar morphology and also very low sequence level genetic diversity for complete chloroplast genomes. Relatively abundant intra-species polymorphisms are identified in Pedicularis chamissonis, Panax ginseng, Scutellaria baicalensis and Rhus chinensis (Fujii et al. 1997; Kim et al. 2015a; Jiang et al. 2017; Joh et al. 2017; Kim et al. 2017). We found very low diversity between both species with their sequence variations, suggesting an on-going genome divergence of the two species. Because of the similar morphology and the sequence level genome similarity, nevertheless, it is required to expand this research by investigating more Eclipta species for solid conclusion and for establishment of clear discrimination criteria.

\section{ACKNOWLEDGEMENTS}

This research was supported by a grant from Ministry of Food and Drug Safety in 2015 (15172MFDS246) and the Bio \& Medical Technology Development Program of the NRF funded by the Korean government, MSIP (NRF2015M3A9A5030733).

\section{REFERENCES}

Allen GC, Flores-Vergara MA, Krasynanski S, Kumar S, Thompson WF. 2006. A modified protocol for rapid DNA isolation from plant tissues using cetyltrimethylammonium bromide. Nat. Protoc. 1: 2320-2325.

Baskaran P, Jayabalan N. 2005. An efficient micropropagation system for Eclipta alba-a valuable medicinal herb. In Vitro Cellular and Developmental Biology-Plant 41: 532-539. 
Cheng Y, de Vicente MC, Meng H, Guo W, Tao N, Deng X. 2005. A set of primers for analyzing chloroplast DNA diversity in Citrus and related genera. Tree Physiol. 25: 661-672.

Chinese Pharmacopoeia Commission. 2010. Pharmacopoeia of the People's Republic of China 2010. Chemical Industry Press.

Chokotia LS, Vashistha P, Sironiya R, Matoli H. 2013. Pharmacological activities of Eclipta alba (L.). International Journal of Research and Development in Pharmacy and Life Sciences 2: 499-502.

Datta K, Singh AT, Mukherjee A, Bhat B, Ramesh B, Burman AC. 2009. Eclipta alba extract with potential for hair growth promoting activity. J. Ethnopharmacol. 124: 450-456.

Dalal S, Kataria SK, Sastry KV, Rana SVS. 2010. Phytochemical screening of methanolic extract and antibacterial activity of active principles of hepatoprotective herb, Eclipta alba. Ethnobotanical leaflets 14: 248-258.

Dhaka N, Kothari SL. 2005. Micropropagation of Eclipta alba (L.) Hassk-an important medicinal plant. In Vitro Cellular and Developmental Biology-Plant 41: 658-661.

Dong W, Liu J, Yu J, Wang L, Zhou S. 2012. Highly variable chloroplast markers for evaluating plant phylogeny at low taxonomic levels and for DNA barcoding. PLoS ONE 7: e35071.

Fujii N, Ueda K, Watano Y, Shimizu T. 1997. Intraspecific sequence variation of chloroplast DNA in Pedicularis chamissonis Steven (Scrophulariaceae) and geographic structuring of the Japanese "Alpine" plants. J. Plant Res. 110: 195-207.

Jang WJ, Kim KY, Kim KH, Lee SC, Park HS, Lee JK, et al. 2015. The complete chloroplast genome sequence of Cynanchum auriculatum Royle ex Wight (Apocynaceae). Mitochondrial DNA Part A 6: 4549-4550.

Jiang D, Zhao Z, Zhang T, Zhong W, Liu C, Yuan Q, et al. 2017. The chloroplast genome sequence of Scutellaria baicalensis provides insight into intraspecific and interspecific chloroplast genome diversity in Scutellaria. Genes 8: 227.

Joh HJ, Kim NH, Jayakodi M, Jang WJ, Park JY, Kim YC, et al. 2017. Authentication of golden-berry $P$. ginseng cultivar 'Gumpoong' from a landrace 'Hwangsook' based on pooling method using chloroplast-derived markers. Plant Breed. Biotech. 5: 16-24.

Kim I, Park JY, Lee YS, Joh HJ, Kang SJ, Jayakodi M, et al. 2017. The complete chloroplast genome sequence and intra-species diversity of Rhus chinensis. Plant Breed. Biotech. 5: 243-251.

Kim K, Lee SC, Lee J, Lee HO, Joh HJ, Kim NH, et al. 2015a. Comprehensive survey of genetic diversity in chloroplast genomes and 45S nrDNAs within Panax ginseng species. PLoS ONE 10: e0117159.

Kim K, Lee SC, Lee J, Yu Y, Yang K, Choi BS, et al. 2015b. Complete chloroplast and ribosomal sequences for 30 accessions elucidate evolution of Oryza AA genome species. Sci. Rep. 5: 15655.

Kim KH, Kim YS, Kim MR, Lee HY, Lee KH, Kim JH, et al. 2015c. Development of primer sets for the detection of Polygonum multiflorum, Cynanchum wilfordii and $C$. auriculatum. Journal of Food Hygiene and Safety 30: 289-294.

Kim MK, Wang HT, KimYJ, Sathiyamoorthy S, Kwon WS, Yang DC. 2013. Molecular authentication by multiplexPCR of three similar medicinal plant species: Cynanchum wilfordii, Cynanchum auriculatum and Polygonum multiflorum (Fallopia multiflorum). Journal of Medicinal Plants Research 7: 2584-2589.

Liu QM, Zhao HY, Zhong XK, Jiang JG. 2012. Eclipta prostrata L. phytochemicals: isolation, structure elucidation, and their antitumor activity. Food Chem. Toxicol. 50: 4016-4022.

Mithun NM, S. Shashidhara, R. Vivek Kumar. 2011. Eclipta alba (L.) A review on its phytochemical and pharmacological profile. Pharmacologyonline 1: 345-357.

Muruganantham S, Anbalagan S, Ramamurthy N. 2009. FT-IR and SEM-EDS comparative analysis of medicinal plants, Eclipta alba Hassk and Eclipta prostrata Linn. Romanian J. Biophys. 19: 285-294.

Neeraja PV, Margaret E. 2012. Eclipta alba (L.) Hassk: a valuable medicinal herb. International Journal of Current Pharmaceutical Review and Research 2: 188-197.

Nielsen LR. 2004. Molecular differentiation within and among island populations of the endemic plant Scalesia affinis (Asteraceae) from the Galápagos Islands. Heredity 93: 434-442.

Parducci L, Szmidt AE, Madaghiele A, Anzidei M, Vendramin GG. 2001. Genetic variation at chloroplast microsatellites (cpSSRs) in Abies nebrodensis (Lojac.) 
Mattei and three neighboring Abies species. Theor. Appl. Genet. 102: 733-740.

Park HS, Kim KY, Kim KH, Lee SC, Lee JK, Seong RS, et al. 2015. The complete chloroplast genome sequence of an important medicinal plant Cynanchum wilfordii (Maxim.) Hemsl. (Apocynaceae). Mitochondrial DNA Part A 5: 3747-3748.
Park JY, Lee YS, Kim JK, Lee HO, Park HS, Lee SC, et al. 2016. The complete chloroplast genome of Eclipta prostrata L.(Asteraceae). Mitochondrial DNA Part B 1: 414-415.

Tamura K, Stecher G, Peterson D, Filipski A, Kumar S. 2013. MEGA6: molecular evolutionary genetics analysis version 6.0. Mol. Biol. Evol. 30: 2725-2729. 